\title{
Associations of Acute Exposure to Airborne Pollutants with COVID-19 Infection: Evidence from China
}

Bingqing Lu

Fudan University

$\mathrm{Na} \mathrm{Wu}$

Fudan University

Jiakui Jiang

Fudan University

Xiang Li ( $\square$ lixiang@fudan.edu.cn )

Fudan University https://orcid.org/0000-0002-0434-3057

\section{Research Article}

Keywords: airborne pollutants, COVID-19, Evidence

Posted Date: March 11th, 2021

DOI: https://doi.org/10.21203/rs.3.rs-273170/v1

License: (c) (i) This work is licensed under a Creative Commons Attribution 4.0 International License. Read Full License 


\section{Abstract}

The outbreak of COVID-19, caused by SARS-CoV-2 has spread across many countries globally. Greatly limited study concerned the effect of airborne pollutants on COVID-19 infection, while exposure to airborne pollutants may harm human health. This paper aimed to examine the associations of acute exposure to ambient atmospheric pollutants to daily newly COVID-19 confirmed cases in 41 Chinese cities. Using a generalized additive model with Poisson distribution controlling for temperature and relative humidity, we evaluated the association between pollutant concentrations and daily COVID-19 confirmation at single-city level and multi-city level. We observed a $10 \mu \mathrm{g} / \mathrm{m}^{3}$ rise in levels of $\mathrm{PM}_{2.5}(\mathrm{lag}$ $0-14), \mathrm{O}_{3}(\operatorname{lag} 0-1), \mathrm{SO}_{2}(\operatorname{lag} 0)$ and $\mathrm{NO}_{2}(\operatorname{lag} 0-14)$ were positively associated with relative risks of 1.050 (95\% Cl: 1.028, 1.073), 1.011 (1.007, 1.015), $1.052(1.022,1.083)$ and $1.094(1.028,1.164)$ of daily newly confirmed cases, respectively. Further adjustment for other pollutants did not change the associations materially (excepting in the model for $\mathrm{SO}_{2}$ ). Our results indicated that COVID-19 incidence may be susceptible to airborne pollutants such as $\mathrm{PM}_{2.5}, \mathrm{O}_{3}, \mathrm{SO}_{2}$ and $\mathrm{NO}_{2}$, and mitigation strategies of environmental factors are required to prevent spreading.

\section{Introduction}

COVID-19, caused by severe acute respiratory syndrome coronavirus 2 (SARS-CoV-2) has spread across the world and many countries are experiencing ongoing local transmission (Ghinai et al. 2020, Götzinger et al. 2020). The World Health Organization (WHO) reported the novel coronavirus pneumonia has afflicted over 110,749,023 people in more than 221 countries throughout the world and killed over 2,455,131 people as of 21 February, 2021. In China, COVID-19 started in Wuhan and spread rapidly across the whole country, and an initial public restrictions has played an important role in limiting the spread of infection (Chinazzi et al. 2020).

Early studies showed that SARS-CoV-2 has a pathogenic mechanism analogous to the SARS coronavirus, causing potential damage to vital organs including the heart, lungs, liver, kidneys (Qiu et al. 2020). Many solid observation evidences confirmed the important role of airborne transmission in the spread of COVID-19 (Doremalen et al. 2020, Liu et al. 2020). Also, air pollution has been recognized to exacerbate the transmission and severity of respiratory viral infections such as MERS and SARS (Domingo \&Rovira 2020, Singh 2016, Yin \&Wunderink 2018). The recent literature described the potential associations between atmospheric pollutants and the outbreak of COVID-19 (Contini \&Costabile 2020, Dutheil et al. 2020). In some Northern Italian areas, the high propagation capacity of SARS-CoV-2 may be related to an elevated level of ambient particulate matter (Martelletti \&Martelletti 2020). A study in 3,122 US counties observed that urban air pollution is likely to increase COVID-19 case-fatality and mortality rates(Liang et al. 2020). In China, more viral infections were found in the areas afflicted by high PM, nitrogen dioxide, carbon monoxide and formaldehyde (Pansini \&Fornacca 2020).

We have long known that acute of chronic exposure to atmospheric pollutants such as $\mathrm{PM}_{2.5}, \mathrm{PM}_{10}$, nitrogen dioxide $(\mathrm{NO})$, ozone $\left(\mathrm{O}_{3}\right)$, sulfur dioxide $\left(\mathrm{SO}_{2}\right)$ and carbon monoxide $(\mathrm{CO})$ may cause 
inflammation with systemic effects, usually in the lung, and induce oxidative stress (Al-Kindi et al. 2020, Bind et al. 2012, Newbury et al. 2019). Past work has suggested that exposure to ambient ground level atmospheric pollutants, such as $\mathrm{PM}_{2.5}$ and $\mathrm{O}_{3}$ can impose a huge burden on the respiratory and cardiovascular system and thus cause many diseases, including stroke, COPD, myocardial infarction, asthma and congestive heart conditions (Ho et al. 2019, Lelieveld et al. 2019, Schraufnagel et al. 2019). In in vitro studies, $\mathrm{NO}_{2}$ has also been reported to correlate with cellular inflammation, bronchial hyperresponsiveness, and increased risk of infection (Koenig 2000). $\mathrm{SO}_{2}$ may contribute to respiratory symptoms in both healthy patients and patients with potential pulmonary disease, particularly causing changes in airway physiology (Chen et al. 2007).

Since SARS-CoV-2 could survive and remain infectious in aerosols for several hours, and may have a significant effect on human morbidity and mortality throughout the world (Van Doremalen et al. 2020), it is crucial to probe the associations between atmospheric pollutants and COVID-19 incidence. The current studies have evaluated the relationship between the individual pollutants and COVID-19 morbidity or mortality in Italy (Zoran et al. 2020), England (Travaglio et al. 2021), the Netherlands (Andree 2020), and America (Wu et al. 2020). However, few studies have focused on the impact of acute atmospheric pollutant exposure on daily COVID-19 incidence in China. For example, Zhu et al. evaluated cumulative lag effects of ambient airborne pollutants with daily COVID-19 confirmed cases using generalized additive models (Zhu et al. 2020). This paper aims to discuss the impacts of airborne pollutants on COVID-19 morbidity in 41 cities in China (excepting Wuhan), controlling for meteorological variables. To evaluate the impacts of these factors on COVID-19 fast diffusion and fatality, time-series values of selected atmospheric and weather variables over the period January 20 - February 29 2020, together with daily newly COVID-19 confirmed cases have been examined.

\section{Methods}

\subsection{Data Collection}

We performed a daily time-series study of the correlations between daily newly COVID-19 confirmed cases and air pollutants exposures. The analysis included COVID-19 confirmed cases that occurred among people of the 41 Chinese cities from January 20 to February 29, 2020, of which the cumulative number of which exceeds 100 and the environmental data are available (excepting Wuhan). Since Wuhan with the largest outbreaks and lack of available test may have under-reported cases, we didn't take Wuhan into account in our data. Data on daily newly COVID-19 confirmed cases for each city over the study period was obtained from the records kept in the local health commissions and reviewed by the National Health Commission of the People's Republic of China.

Values of daily 24-h average levels of ambient $\mathrm{PM}_{2.5}, \mathrm{PM}_{10}, \mathrm{SO}_{2}, \mathrm{NO}_{2}$ and $\mathrm{CO}$ as well as daily 8-h mean levels of $\mathrm{O}_{3}$ for each city were obtained from https://www.aqistudy.cn/. We averaged the valid monitoring data of selected airborne pollutants in each city, and obtained the daily mean levels of the pollutants. 
Meanwhile, we gathered daily average temperature and average relative humidity data for each city from http://pm.kksk.org/ to control for the miscellaneous effects of weather conditions.

\subsection{Statistical analysis}

We assessed the detrimental effects of airborne pollutants on COVID-19 incidence using a two-stage analysis strategy which has been widely applied in multicity time-series research (Chen et al. 2017, Liu et al. 2018). To be specific, the relationship between daily COVID-19 confirmation and pollutants $\left(\mathrm{PM}_{2.5}, \mathrm{O}_{3}\right.$, $\mathrm{SO}_{2}$ and $\mathrm{NO}_{2}$ ) was assessed in separate models for each city using generalized additive Poisson models (GAM) at first stage. At second stage, a random-effects meta-analysis was undertaken to pool the effect estimates at the multicity level. The models were applied to each pollutant separately.

In stage 1, GAM were used in the scope of distributed lag linear modeling framework to approximate cityspecific effects of pollutants on COVID-19 morbidity. The model includes the following explanatory variables: (1) log (the number of people newly infected with SARS-CoV-2 every day); (2) the day of the week, which takes into account possible variations within a week; (3) smooth functions of elapsed time to adjust for time varying influences on COVID-19 morbidity; and (4) smooth functions of mean temperature and mean relative humidity on the same day to correct for possible nonlinear and lagged confounding effects of weather conditions. The basic model was shown by Eq. (1):

$\log E\left(Y_{n}\right)=\beta Z_{n}+\mathrm{s}\left(\mathrm{time}_{n}, \mathrm{df}\right)+\mathrm{s}\left(T E M P_{n}, \mathrm{df}\right)+\mathrm{s}\left(\mathrm{RH}_{n}, \mathrm{df}\right)+\mathrm{DOW}_{n}$

where $E\left(Y_{n}\right)$ is the expected count of daily newly COVID-19 confirmed cases on day $n ; \beta$ is the regression coefficient; $Z_{n}$ is the level of selected pollutants on the day $n$; time ${ }_{n}$ is the variable for time with a df natural cubic spline on day $n$ to control for long-term trends; TEMP and RH are the mean temperature and mean relative humidity on day $n$ with a df natural cubic spline; $\mathrm{DOW}_{n}$ and is the variable for the day $n$. Using the residual partial autocorrelation function plots (PACF) and lower generalized cross-validation (GCV) values, the appropriate df value was selected (Amini et al. 2019). This model was applied to each city and air pollutants separately. In this stage, we set 14 as maximum lag day of air pollutants because the incubation period of COVID-19 can vary from 2-14 days, mostly 3-7 days (Lauer et al. 2020, Lin \&Li 2020).

In stage 2, a meta-analysis of random effects was performed to combine the city-specific effect estimates, thus we obtained the estimates of the immediate effects of air pollutants at the multi-city average level. We calculated the delayed and cumulative effects of airborne pollutants on daily new COVID-19 incidence and presented as relative risks (RRs) and corresponding 95\% confidence intervals (Cls) associated with a $10 \mu \mathrm{g} / \mathrm{m}^{3}$ rise in levels of the pollutants.

Further to the primary model, we also fitted two-pollutant models which each included adjustment to one other pollutant. The correlation between airborne pollutants concentrations and COVID-19 morbidity was considered valid if there is no significant difference between the effect estimates of the single-pollutant 
and two-pollutant models. We also conducted stratified analyses to evaluate the feasible the pollutants COVID-19 incidence association by case location. The location of case was categorized into cities in Hubei and cities outside Hubei.

All statistical analyses were completed using R3.6.3 software. Two-sided statistical tests were used, and the statistical significance was set at $p$-value $<0.05$.

\section{Results}

Figure 1 shows the positions of the 41 cities studied in the PRC and the descriptive statistics on cumulative COVID-19 confirmed cases are shown in Table S1. From January 20 to February 29, 2020, there was a total of 22970 confirmed cases for COVID-19 in the 41 cities, 16687 (72.6\%) of cases were detected in cities in Hubei, and 6283 (27.4\%) were reported in other provinces. Xiaogan was the highest of the 12 cities in Hubei with about 3451 COVID-19 confirmed cases while Enshi was the lowest city with 258 confirmed cases. Among the 21 cities outside Hubei included in this study, Chongqing had the highest number of confirmed cases $(n=576)$, whereas the lowest confirmed cases were observed in Shaoyang $(n=136)$.

Table 1 provides a description of all atmospheric and weather variables recorded over the period covered by this research. The daily mean $\mathrm{PM}_{2.5}$ level was $51.0 \mu \mathrm{g} / \mathrm{m}^{3}$, which has exceeded the daily concentration limit set in the Ministry of Ecology and Environment of China on ambient air quality of $35 \mu \mathrm{g} / \mathrm{m}^{3}$ and $>2$ times above than the WHO guideline of $25 \mu \mathrm{g} / \mathrm{m}^{3}$. Analogously, the mean value of $\mathrm{PM}_{10}\left(62.4 \mu \mathrm{g} / \mathrm{m}^{3}\right)$ was higher than the Chinese standard and the WHO guideline of $\left(50 \mu \mathrm{g} / \mathrm{m}^{3}\right)$. The levels of other pollutants were lower than the Chinese standards and the $\mathrm{WHO}$ guideline. The mean value of $\mathrm{O}_{3}, \mathrm{NO}_{2}$, $\mathrm{SO}_{2}$ and $\mathrm{CO}$ were $75.9 \mu \mathrm{g} / \mathrm{m}^{3}, 18.8 \mu \mathrm{g} / \mathrm{m}^{3}, 7.7 \mu \mathrm{g} / \mathrm{m}^{3}$ and $0.9 \mathrm{mg} / \mathrm{m}^{3}$, respectively. As a response to COVID-19 lockdown and declining economic activity, $\mathrm{NO}_{2}, \mathrm{SO}_{2}$ and $\mathrm{CO}$ declined sharply while $\mathrm{O}_{3}$ kept steady or even increased(Chu et al. 2021, Pei et al. 2020). The average daily temperature was $7.6^{\circ} \mathrm{C}$, varying from -22.5 to $23.0^{\circ} \mathrm{C}\left(\mathrm{IQR}\right.$ of $\left.5.3^{\circ} \mathrm{C}\right)$; for relative humidity, the average was $74.7 \%$, with IQR of $21.5 \%$.

Spearman correlation coefficients for pollutant and meteorological variable pairs for the study period are given in Table 2. Across the study period, $\mathrm{PMO}_{2.5}$ concentrations were closely correlated with $\mathrm{PM}_{10}$ concentrations (Pearson's correlation coefficient $r=0.793)$, but less so with $\mathrm{CO}(r=0.563)$, with both $\mathrm{NO}_{2}$ and $\mathrm{SO}_{2}$ ( $r=0.414$ and 0.365 , respectively), and only weakly correlated with $\mathrm{O}_{3}(r=0.196) . \mathrm{O}_{3}$ was weakly correlated with other pollutants, whereas the highest correlation coefficient of 0.196 with $\mathrm{PM}_{2.5}$. For other pollutants $\left(\mathrm{NO}_{2}, \mathrm{SO}_{2}\right.$ and $\left.\mathrm{CO}\right)$, the pattern of correlations was broadly analogous. In addition, temperature and relative humidity were negatively correlated with all pollutants. Since the Spearman rank order correlation analyses indicated a high correlation between temperature and relative humidity and several air pollutants, we incorporated these meteorological factors into the models to assess their underlying confounding effects. 
Figure 2 gives the pooled relative risk in daily newly COVID-19 confirmed cases (and 95\% Cls) associated with a $10 \mu \mathrm{g} / \mathrm{m}^{3}$ rise in airborne pollutants for single day lags from lag of 0 to 7 . In the main model for $\mathrm{PM}_{2.5}$, each $10 \mu \mathrm{g} / \mathrm{m}^{3}$ elevation of exposure to $\mathrm{PM}_{2.5}$ was observed to coincide a small increase in daily newly COVID-19 confirmed cases in the same day (lag 0), with RR $(95 \% \mathrm{Cl})$ of $1.005(1.001,1.011)$. For longer lags the RR increased gradually until lag 4, reaching a maximum of $1.010(1.004,1.016)$ before decreasing. We observed positive associations between $\mathrm{O}_{3}$ and daily newly COVID-19 confirmed cases from lag of 0 to 5 with the strongest RR $(95 \% \mathrm{Cl})$ of $1.011(1.007,1.014)$ at lag 0 . Fewer remarkable findings were observed in the model for $\mathrm{SO}_{2}$, with significant positive associations of $\mathrm{SO}_{2}$ and daily newly COVID-19 confirmed cases at lag 0 [1.052 (1.022, 1.083)], lag 1 [1.032 $(1.001,1.063)]$ and lag $3[1.044$ $(1.007,1.082)]$. In addition, there was no association between increases in $\mathrm{NO}_{2}$ and COVID-19 outcomes at any single-day lag. Generally, associations with daily newly COVID-19 confirmed cases tended to be positive for single-day lags and the RRs were slightly for $\mathrm{PM}_{2.5}$ than $\mathrm{O}_{3}$, both less than $\mathrm{SO}_{2}$.

Since prominent correlations between atmospheric pollutants and COVID-19 incidence were observed at several moving averages lags (Table 3), the cumulative effects were further examined. City-specific and the strongest pooled effect estimates of daily newly COVID-19 confirmed cases with increases in the 14-day average of $\mathrm{PM}_{2.5}$ and $\mathrm{NO}_{2}$ are presented in Figure $3 \mathrm{a}$ and $3 \mathrm{~b} . \mathrm{PM}_{2.5}$ and $\mathrm{NO}_{2}$ significantly increased the risk of daily COVID-19 incidence at lag 0-14 [1.050 $(1.028,1.073)$ and $1.094(1.028,1.164)$, respectively]. For individual cities, the city-specific estimates of the relative risks in daily newly COVID-19 confirmed cases varied greatly, ranging from 0.230 (for Bozhou) to 1.386 (for Guangzhou) in $\mathrm{PM}_{2.5}$ concentration and ranging from 0.578 (for Tianjin) to 3.880 (for Changsha) in $\mathrm{NO}_{2}$ concentration. As shown in Fig. $3 \mathrm{c}$, each $10 \mu \mathrm{g} / \mathrm{m}^{3}$ increase in $\mathrm{O}_{3}$ was associated with daily newly COVID-19 confirmed cases in lag $0-1$ and the pooled RR $(95 \% \mathrm{Cl})$ was $1.011(1.007,1.015)$. In the city-level, the highest RRs of $\mathrm{O}_{3}$ were observed in Jingmen, Ezhou and Taizhou, while the lowest RRs were observed in Shaoyang and Jiujiang.

We analyzed two-pollutant models for air pollutants to test interdependences of the pollutants. In such models with $\mathrm{PM}_{2.5}$ as one thereof, the RRs were generally unchanged or increased except adjusting for $\mathrm{PM}_{10}$, compared with the value in the single pollutant models (Figure 4a). Similarly, in models with $\mathrm{O}_{3}$ as one of the pollutants, the RRs were generally unchanged or slightly increased compared with its value in the single pollutant model (Figure 4b). However, the associations between $\mathrm{SO}_{2}$ (Figure 4c) or $\mathrm{NO}_{2}($ Figure 4d) and risk of COVID-19 incidence were no longer significant at some lags in two-pollutant models (except for $\mathrm{O}_{3}$ and $\mathrm{NO}_{2}$ ). The effects of $\mathrm{SO}_{2}$ were stronger after adjusting for $\mathrm{NO}_{2}$ but were non-significant after adjusting for other pollutants $\left(\mathrm{PM}_{2.5}, \mathrm{PM}_{10}, \mathrm{O}_{3}\right.$ and $\left.\mathrm{CO}\right)$. Each $10 \mu \mathrm{g} / \mathrm{m}^{3}$ rise in concentration of $\mathrm{SO}_{2}$ at lag 0 coincided with an increase of $2.6 \%[95 \% \mathrm{Cl}(1.5,3.9)]$ risk of COVID-19 incidence after adjusting for $\mathrm{NO}_{2}$. Similarly, each $10 \mu \mathrm{g} / \mathrm{m}^{3}$ rise in concentration of $\mathrm{NO}_{2}$ at lag $0-14$ coincided with an exacerbation of $0.6 \%[95 \% \mathrm{Cl}(-0.9,2.3)]$ risk of COVID-19 incidence after adjusting for $\mathrm{O}_{3}$. Overall, $\mathrm{PM}_{2.5}$ had the most robust association with daily newly COVID-19 confirmed cases when adjusted for confounding by other pollutants. 
Since Hubei was the province with the most severe COVID-19 outbreak, stratified analysis by regions showed that somewhat larger RRs in cities in Hubei than in cities outside Hubei (Table S2). In cities in Hubei, the associations remained positive and significant for most pollutants. Notably, positive associations were also founded for $\mathrm{O}_{3}$ at lag0-1 for cities outside Hubei, while no prominent effects were observed for other pollutants. Overall, the maximum cumulative RRs were found in cities in Hubei, which were $1.094(95 \% \mathrm{Cl}: 1.064,1.124)$ for $\mathrm{PM}_{2.5}$ at lag $0-14 ; 1.016(95 \% \mathrm{Cl}: 1.011,1.021)$ for $\mathrm{O}_{3}$ at lag $0-1$; $1.080(95 \% \mathrm{Cl}: 1.045,1.117)$ for $\mathrm{SO}_{2}$ at lag 0 ; and $1.213(95 \% \mathrm{Cl}: 1.085,1.356)$ for $\mathrm{NO}_{2}$ at lag $0-14$, respectively. Our result is consistent with the findings of the study by Wang et al., who found the correlations between COVID-19 and ambient PM were stronger for cities inside Hubei than those outside Hubei, and had the highest RR at lag 0-14 for $\mathrm{PM}_{2.5}$ (Wang et al. 2020).

\section{Discussion}

To date, epidemiologic evidence regarding the underlying relationships of ambient atmospheric pollutants on COVID-19 outbreak is insufficient. In this study, we analyzed multisite data on airborne pollutants and daily newly COVID-19 confirmed cases in 41 Chinese cities, although Wuhan (the worst affected city of China) was not included. We observed modest correlations between daily newly COVID-19 confirmed cases and acute exposure to $\mathrm{NO}_{2}$, and to a lesser extent, with $\mathrm{PM}_{2.5}, \mathrm{O}_{3}$ and $\mathrm{SO}_{2}$. In the analysis of main models for pollutants, we observed the RRs $(95 \% \mathrm{Cl})$ for the associations between daily newly COVID-19 confirmed cases and $\mathrm{PM}_{2.5}, \mathrm{O}_{3}, \mathrm{SO}_{2}$ and $\mathrm{NO}_{2}$ were $1.050(1.028,1.073)$ at lag $0-14$, $1.011(1.007,1.015)$ at lag $0-1,1.052(1.022,1.083)$ at lag 0 and $1.094(1.028,1.164)$ at lag $0-14$ per each $10 \mu \mathrm{g} / \mathrm{m}^{3}$ increment, respectively. These results conform the assumption that viruses attach to air pollutants (Reche et al. 2018) and pollutants actually act as the airborne medium of SARS-CoV-2 (Contini \&Costabile 2020), potentially explaining the spread of SARS-CoV-2 and its infectious capacity.

Some research has shown that acute exposure to air pollutants is correlated with COVID-19 prevalence or fatality. For example, a meta-analysis by $\mathrm{Cao}$ et al. based on estimates from 71 cities across China reported an increase of interquartile range in $\mathrm{PM}_{2.5}, \mathrm{O}_{3}, \mathrm{SO}_{2}$ and $\mathrm{NO}_{2}$ at lag 4 corresponding to 1.40 (1.37, 1.43), $1.28(1.27,1.29), 1.01(1.00,1.02)$ and $1.08(1.07,1.10)$ odd ratios of daily COVID-19 confirmation, respectively (Cao et al. 2020). Study conducted carried out in 120 cities across China revealed increases in daily counts of confirmed cases of $2.24 \%, 4.76 \%,-7.79 \%$ and $6.94 \%$ each $10 \mu \mathrm{g} / \mathrm{m}^{3}$ increment in $\mathrm{PM}_{2.5}$, $\mathrm{O}_{3}, \mathrm{SO}_{2}$ and $\mathrm{NO}_{2}$ as well (Zhu et al. 2020). Comparing our results to the aforementioned analysis, our findings for $\mathrm{SO}_{2}$ and COVID-19 incidence are completely opposite to their results. It is not clear why the correlations between air pollution and daily COVID-19 morbidity would be different in our study from associations reported by different studies, but it might be explained by factors such as the different scale of the study city and amount of data, fewer considered meteorological variables, and relative higher concentrations and big fluctuation of pollutants during study period (Li \&Chen 2020). Futhermore, uncontrolled residual confounding or chance as possible explanations should also be considered. 
Moreover, several multi-city studies about individual pollutants have also been reported. A multi-city study (Wang et al. 2020) in 72 cities (excluding Wuhan) reported a summary estimate for daily COVID-19 confirmed cases of $1.016(1.015,1.018)$ per $10 \mu \mathrm{g} / \mathrm{m}^{3}$ rise in the level of $\mathrm{PM}_{2.5}$ at lag 0-14. A national American analysis observed a significant increment of $7.1 \%(1.2 \%, 13.4 \%)$ and $11.2 \%(3.4 \%, 19.5 \%)$ in COVID-19 case-fatality and mortality per IQR in $\mathrm{NO}_{2}$ (Liang et al. 2020). In England, studies also reported increases in COVID-19 incidence in addition to mortality alongside rises in $\mathrm{NOx}$ or $\mathrm{SO}_{2}$, meaning regional variations in the two pollutants may predict the numbers of COVID-19 cases and death (Travaglio et al. 2021). A study conducted in 120 Chinese cities (excluding Wuhan) by multivariate negative binomial regression implicated the increased number of COVID-19 confirmed cases was accompanied by acute exposure to elevated levels of $\mathrm{PM}_{2.5}$ and $\mathrm{O}_{3}$ and reduced levels of $\mathrm{SO}_{2}$ (Zhou et al. 2021). It should be noted that some studies summarized above reported a negative significant association between $\mathrm{SO}_{2}$ and COVID-19 incidence, this may due to the relatively low levels of $\mathrm{SO}_{2}$. Our two-pollutant models found a non-significant association between $\mathrm{SO}_{2}$ and COVID-19 incidence after adjusting for other pollutants such as $\mathrm{PM}_{2.5}$ and $\mathrm{O}_{3}$, suggesting that the mechanism of the interaction between $\mathrm{SO}_{2}$ and other pollutants should be explored in future studies.

Whether the observed correlations between air pollutants are independent of other pollutants is a significant issue for air quality control and health risk assessment. In the present study, although the degree of the correlation between $\mathrm{PM}_{2.5}$ and $\mathrm{O}_{3}$ has changed in two-pollutant models, the correlation between the two remained mostly significant, which provides evidence supporting the independent health impacts of $\mathrm{PM}_{2.5}$ and $\mathrm{O}_{3}$. It is remarkable that the estimates of relative risk of COVID-19 incidence per 10 $\mu \mathrm{g} / \mathrm{m}^{3}$ rise with the decrease of $\mathrm{PM}_{2.5}$ levels and has no significant effects, a finding that may reflect the close correlations of $\mathrm{PM}_{2.5}$ with $\mathrm{PM}_{10}$ caused by similar sources. As for $\mathrm{SO}_{2}$, the two-pollutant models indicated that the estimated effect of $\mathrm{SO}_{2}$ on COVID-19 incidence was attributable to confounding by other air pollutants (except $\mathrm{NO}_{2}$ ). In addition, although $\mathrm{NO}_{2}$ are key $\mathrm{O}_{3}$ precursors (Naja \&Lal 2002), the two-pollutant model indicated $\mathrm{NO}_{2}$ has a strong and independent influence on COVID-19 incidence, meaning that the influence of $\mathrm{NO}_{2}$ may not mediated by $\mathrm{O}_{3}$.

Previous experiments on coronaviruses in controlled conditions show that it can survive at around $4^{\circ} \mathrm{C}$ and a relative humidity of $20-80 \%$, and inactivates rapidly above $20^{\circ} \mathrm{C}$ (Casanova et al. 2010). It seems that specific climate conditions, especially ambient temperature and humidity modulate the survival and spread of SARS-CoV-2. A systematic review suggested that warm and humid climates seem to weaken the transmission of COVID-19 while the certainty of the evidence produced was graded as low (Mecenasl et al. 2020). Analogously, a time-series analysis in mainland China found with a relative humidity of $67 \%$ $-85.5 \%$, every $1^{\circ} \mathrm{C}$ elevation in temperature resulted in a decrease in the daily confirmed cases of $36 \%$ $-57 \%$ (Qi et al. 2020). A global study also reported that the incidence of COVID-19 decreased by $6 \%$ and $3 \%$ after adjusting for daily maximum temperature and $\mathrm{RH}$ (Islam et al. 2020), while Wan et al. found the transmission capacity of COVID-19 peaked about $6.3^{\circ} \mathrm{C}$ and then decreased under high temperature conditions of human intervention (Wan et al. 2020). Contrary to the above conclusion, a study across 
China suggests that the spread speed of the COVID-19 outbreak is independent of temperature, while the temperature-dependence of the propagation reported in earlier related work was likely to be an artifact since the temperature-dependence blurred with a prevailing zonal pattern of spread across the northtemperature zone, reflecting the primary patterns of human activities (Jamil et al. 2020). Pawar also indicates that although a strong relationship between recovered cases and death cases was observed, changes in temperature showed no significant correlation with confirmed cases in China by linear regression models (Pawar et al. 2020). In addition, ultraviolet photons has also been considered to play the possible role in the modulation of COVID-19 epidemiology (Nicastro et al. 2020).

The underlying pathophysiological mechanism for developing COVID-19 is perplexing and very few toxicological literature on biological plausibility have been published. It has been reported (Frontera et al. 2020) that chronic exposure to $\mathrm{PM}_{2.5}$ leads to overexpression of alveolar angiotensin-converting enzyme 2 (ACE-2) receptor, which is crucial in protecting lung from air pollution (Alifano et al. 2020, Lin et al. 2018), as well as the main receptor of SARS-CoV-2 (Zhou et al. 2020). This may increase the viral load in a body exposed to pollutants, thus occupying ACE-2 receptors and weakening host defenses.

Furthermore, exposure to $\mathrm{NO}_{2}$ may bring a second hit after exposure to $\mathrm{PM}_{2.5}$, causing severe forms of SARS-CoV-2 to appear in the lungs where ACE-2 depleted, leading to worse results. The current toxicology literature suggests that exposure to ambient ground level ozone is pertinent to the emergence of respiratory diseases such as asthma, influenza and SARS (Zoran et al. 2020). $\mathrm{O}_{3}$ is a potential oxidizer and may induce oxidative stress, which may harm the immune systems and organs such as lung and heart, by changing the host's resistance to viral and bacterial infections (Ciencewicki \&Jaspers 2007). A study in northern Italy (Conticini et al. 2020) has shown that an overexpression of IL-8, IL-17 and TNF-a, induced by $\mathrm{O}_{3}$, contributes to prolonged systemic and respiratory system inflammation and eventually leads to an innate immune system hyper-activation. Compared to $\mathrm{PM}_{2.5}$ and $\mathrm{O}_{3}$, fewer research has studied the biological pathways of harmful effects of $\mathrm{NO}_{2}$ and $\mathrm{SO}_{2}$. The virological explanation might be that $\mathrm{NO}_{2}$ causes the reactions of components in the airway surface fluids (ASF) of the respiratory tract and lungs, resulting in highly reactive proteins and lipid oxidation products that can cause inflammation by subsequently damaging epithelial cells through secondary reactions (Gamon \&Wille 2016). Another study by Chauhan et al.(Chauhan et al. 2003) has done research on the relation between $\mathrm{NO}_{2}$ exposure and respiratory disease caused by proven respiratory viral infections including coronavirus.

Our study indicates that air pollutants are important in analyzing the pathogenesis of COVID-19 and that the effect of air pollutants on the disease deserves more attention. It is also subject to some limitations. Primarily, the correlations between air pollutants and COVID-19 confirmation were affected by many other factors, such as strict prevention measure and population migration. Secondly, as the definitions of COVID-19 cases changed at different stage of the epidemic, the number of COVID-19 confirmed cases may be affected. Next, we only focused on cities across China where the cumulative COVID-19 confirmed cases exceeds 100 and the environmental data are available (except Wuhan) during the study period, so the estimate of air pollutants effects cannot be generalized to other countries. Finally, stratified analysis by gender or age on were not analyzed in our study due to a lack of detailed information on each 
infectious case. Future studies should be developed to overcome these limitations and the mechanisms of the impact on COVID-19 risk deserve further study.

\section{Conclusion}

In conclusion, our data show that daily COVID-19 confirmed cases are positively correlated with shortterm exposure to atmospheric pollutants, such as $\mathrm{PM}_{2.5}, \mathrm{O}_{3}, \mathrm{SO}_{2}$ and $\mathrm{NO}_{2}$ in 41 cities across China, and the robust associations between $\mathrm{PM}_{2.5}$ or $\mathrm{O}_{3}$ and daily newly COVID-19 confirmed cases were not complicated by the other air contaminants assessed. Exposure to $\mathrm{NO}_{2}$ for the 14 - day average concentration exhibited the most obvious cumulative lagged effect on daily COVID-19 confirmed cases. These results can lay the foundation for the study of correlations between airborne pollutant exposure and potential health risks of COVID-19. The effects of atmospheric pollutants on COVID-19 incidence exhibited positive variation, suggesting that not only extensive public health control measures, but also the lag effect of ambient air pollutants should be considered for curbing COVID-19 infection.

\section{Declarations}

\section{Acknowledgements}

This work was partially supported by the National Natural Science Foundation of China (No. 21876029 and 91843301).

Ethical Approval Not applicable

Consent to participate Not applicable

Consent to Publish Not applicable

Authors' contributions B.Q. Lu and N. Wu performed the data analyses, and X. Li revised the manuscript. J.K. Jiang conceived and designed the experiments.

Funding information Funding for this study was provided by the National Natural Science Foundation of China (No. 21876029 and 91843301).

Competing Interests The authors declare that they have no competing interests.

Availability of data and materials Not applicable

\section{References}

1. Al-Kindi SG, Brook RD, Biswal S, Rajagopalan S (2020): Environmental determinants of cardiovascular disease: lessons learned from air pollution. Nature Reviews Cardiology 17, 656-672 
2. Alifano $M$, Alifano $P$, Forgez $P$, lannelli $A$ (2020): Renin-angiotensin system at the heart of COVID-19 pandemic. Biochimie 174, 30-33

3. Amini H, Trang Nhung NT, Schindler C, Yunesian M, Hosseini V, Shamsipour M, Hassanvand MS, Mohammadi Y, Farzadfar F, Vicedo-Cabrera AM, Schwartz J, Henderson SB, Künzli N (2019): Shortterm association setween daily mortality and ambient particulate matter, nitrogen dioxide, and the air quality index in a Middle Eastern megacity. Environmental Pollution 254, 113121

4. Andree BPJ (2020): Incidence of COVID-19 and Connections with Air Pollution Exposure: Evidence from the Netherlands. Policy Research Working Paper Series

5. Bind MA, Baccarelli A, Zanobetti A, Tarantini L, Suh H, Vokonas P, Schwartz J (2012): Air Pollution and Markers of Coagulation, Inflammation, and Endothelial Function Associations and Epigeneenvironment Interactions in an Elderly Cohort. Epidemiology 23, 332-340

6. Cao H, Li B, Gu T, Liu X, Meng K, Zhang L (2020): Associations of ambient air pollutants and meteorological factors with COVID-19 transmission in 31 Chinese provinces: A time-series study

7. Casanova LM, Jeon S, Rutala WA, Weber DJ, Sobsey MD (2010): Effects of air temperature and relative humidity on coronavirus survival on surfaces. Appl Environ Microbiol 76, 2712-2717

8. Chauhan AJ, Inskip HM, Linaker CH, Smith S, Schreiber J, Johnston SL, Holgate ST (2003): Personal exposure to nitrogen dioxide (NO2) and the severity of virus-induced asthma in children. The Lancet 361, 1939-1944

9. Chen R, Yin P, Meng X, Liu C, Wang L, Xu X, Ross JA, Tse LA, Zhao Z, Kan H, Zhou M (2017): Fine Particulate Air Pollution and Daily Mortality: A Nationwide Analysis in 272 Chinese Cities. American Journal of Respiratory \& Critical Care Medicine 196, 73-81

10. Chen T-M, Kuschner WG, Gokhale J, Shofer S (2007): Outdoor Air Pollution: Nitrogen Dioxide, Sulfur Dioxide, and Carbon Monoxide Health Effects. The American Journal of the Medical Sciences 333, 249-256

11. Chinazzi M, Davis JT, Ajelli M, Gioannini C, Litvinova M (2020): The effect of travel restrictions on the spread of the 2019 novel coronavirus (COVID-19) outbreak. Science 368, 395-400

12. Chu B, Zhang S, Liu J, Ma Q, He H (2021): Significant concurrent decrease in PM2.5 and NO2 concentrations in China during COVID-19 epidemic. Journal of Environmental Sciences 99, 346-353

13. Ciencewicki J, Jaspers I (2007): Air Pollution and Respiratory Viral Infection. Inhalation Toxicology $19,1135-1146$

14. Conticini E, Frediani B, Caro D (2020): Can atmospheric pollution be considered a co-factor in extremely high level of SARS-CoV-2 lethality in Northern Italy? Environmental Pollution 261, 114465

15. Contini D, Costabile F (2020): Does Air Pollution Influence COVID-19 Outbreaks? Atmosphere 11, 377

16. Domingo JL, Rovira J (2020): Effects of air pollutants on the transmission and severity of respiratory viral infections. Environmental Research 187, 109650

17. Doremalen NV, Bushmaker T, Morris DH, Holbrook MG, Munster VJ (2020): Aerosol and surface stability of SARS-CoV-2 as compared with SARS-CoV-1. New England Journal of Medicine 382 
18. Dutheil F, Baker JS, Navel V (2020): COVID-19 as a factor influencing air pollution? Environmental Pollution 263, 114466

19. Frontera A, Cianfanelli L, Vlachos K, Landoni G, Cremona G (2020): Severe air pollution links to higher mortality in COVID-19 patients: The "double-hit" hypothesis. Journal of Infection 81, 255-259

20. Gamon LF, Wille U (2016): Oxidative Damage of Biomolecules by the Environmental Pollutants NO2• and NO3. Accounts of Chemical Research 49, 2136-2145

21. Ghinai I et al. (2020): First known person-to-person transmission of severe acute respiratory syndrome coronavirus 2 (SARS-CoV-2) in the USA. The Lancet 395, 1137-1144

22. Götzinger F et al. (2020): COVID-19 in children and adolescents in Europe: a multinational, multicentre cohort study. The Lancet Child \& Adolescent Health 4, 653-661

23. Ho S-C, Chuang K-J, Lee K-Y, Chen J-K, Wu S-M, Chen T-T, Lee C-N, Chang C-C, Feng P-H, Chen K-Y, Su C-L, Tsai C-Y, Chuang H-C (2019): Chronic obstructive pulmonary disease patients have a higher risk of occurrence of pneumonia by air pollution. Science of The Total Environment 677, 524-529

24. Islam N, Shabnam S, Erzurumluoglu AM (2020): Temperature, humidity, and wind speed are associated with lower Covid-19 incidence. medRxiv, 2020.03.27.20045658

25. Jamil T, Alam I, Gojobori T, Duarte CM (2020): No Evidence for Temperature-Dependence of the COVID-19 Epidemic. Frontiers in public health 8, 436-436

26. Koenig JQ (2000): Health Effects of Ambient Air Pollution. Springer, Boston, MA

27. Lauer SA, Grantz KH, Bi Q, Jones FK, Zheng Q, Meredith HR, Azman AS, Reich NG, Lessler J (2020): The Incubation Period of Coronavirus Disease 2019 (COVID-19) From Publicly Reported Confirmed Cases: Estimation and Application. Annals of Internal Medicine 172, 577-582

28. Lelieveld J, Klingmüller K, Pozzer A, Burnett RT, Haines A, Ramanathan V (2019): Effects of fossil fuel and total anthropogenic emission removal on public health and climate. Proceedings of the National Academy of Sciences 116, 7192-7197

29. Li w, Chen X (2020): The nexus of travel restriction, air pollution and COVID-19 infection: Investigation from a megacity of the southern China. medRxiv, 2020.04.25.20079335

30. Liang D, Shi L, Zhao J, Liu P, Sarnat JA, Gao S, Schwartz J, Liu Y, Ebelt ST, Scovronick N, Chang HH (2020): Urban Air Pollution May Enhance COVID-19 Case-Fatality and Mortality Rates in the United States. The Innovation 1, 100047

31. Lin Cl, Tsai CH, Sun YL, Hsieh WY, Lin YC, Chen CY, Lin CS (2018): Instillation of particulate matter 2.5 induced acute lung injury and attenuated the injury recovery in ACE2 knockout mice. International Journal of Biological Sciences 14, 253-265

32. Lin L, Li T (2020): Interpretation of "Guidelines for the Diagnosis and Treatment of Novel Coronavirus (2019-nCoV) Infection by the National Health Commission (Trial Version 5)". Zhonghua yi xue za zhi 100, E001

33. Liu C, Yin P, Chen R, Meng X, Wang L, Niu Y, Lin Z, Liu Y, Liu J, Qi J, You J, Kan H, Zhou M (2018): Ambient carbon monoxide and cardiovascular mortality: a nationwide time-series analysis in 272 
cities in China. The Lancet Planetary Health 2, e12-e18

34. Liu Y, Ning Z, Chen Y, Guo M, Liu Y, Gali NK, Sun L, Duan Y, Cai J, Westerdahl D, Liu X, Xu K, Ho K-f, Kan H, Fu Q, Lan K (2020): Aerodynamic analysis of SARS-CoV-2 in two Wuhan hospitals. Nature $582,557-560$

35. Martelletti L, Martelletti P (2020): Air Pollution and the Novel Covid-19 Disease: a Putative Disease Risk Factor. SN Comprehensive Clinical Medicine 2, 383-387

36. Mecenasl P, Bastos RTdRM, Carlos A, Vallinoto Rr, Normando D (2020): Effects of temperature and humidity on the spread of COVID-19: A systematic review. PLOS ONE 15, e0238339

37. Naja M, Lal S (2002): Surface ozone and precursor gases at Gadanki (13.5 degrees N, 79.2 degrees E), a tropical rural site in India. Journal Of Geophysical Research-Atmospheres 107, 13

38. Newbury JB, Arseneault L, Beevers S, Kitwiroon N, Roberts S, Pariante CM, Kelly FJ, Fisher HL (2019): Association of Air Pollution Exposure With Psychotic Experiences During Adolescence. Jama Psychiatry 76, 614-623

39. Nicastro F, Sironi G, Antonello E, Bianco A, Biasin M, Brucato JR, Ermolli I, Pareschi G, Salvati M, Tozzi P, Trabattoni D, Clerici M (2020): Modulation of COVID-19 Epidemiology by UV-B and -A Photons from the Sun. medRxiv, 2020.06.03.20121392

40. Pansini R, Fornacca D (2020): COVID-19 higher morbidity and mortality in Chinese regions with lower air quality. medRxiv, 2020.05.28.20115832

41. Pawar s, Stanam A, Chaudhari M, Rayudu D (2020): Effects of temperature on COVID-19 transmission. medRxiv, 2020.03.29.20044461

42. Pei Z, Han G, Ma X, Su H, Gong W (2020): Response of major air pollutants to COVID-19 lockdowns in China. Science of The Total Environment 743, 140879

43. Qi H, Xiao S, Shi R, Ward MP, Chen Y, Tu W, Su Q, Wang W, Wang X, Zhang Z (2020): COVID-19 transmission in Mainland China is associated with temperature and humidity: A time-series analysis. Science of The Total Environment 728, 138778

44. Qiu H, Wu J, Hong L, Luo Y, Song Q, Chen D (2020): Clinical and epidemiological features of 36 children with coronavirus disease 2019 (COVID-19) in Zhejiang, China: an observational cohort study. The Lancet Infectious Diseases 20, 689-696

45. Reche I, D'Orta G, Mladenov N, Winget DM, Suttle CA (2018): Deposition rates of viruses and bacteria above the atmospheric boundary layer. The ISME journal 12, 1154-1162

46. Schraufnagel DE, Balmes JR, Cowl CT, De Matteis S, Jung SH, Mortimer K, Perez-Padilla R, Rice MB, Riojas-Rodriguez H, Sood A, Thurston GD, To T, Vanker A, Wuebbles DJ (2019): Air Pollution and Noncommunicable Diseases A Review by the Forum of International Respiratory Societies' Environmental Committee, Part 1: The Damaging Effects of Air Pollution. Chest 155, 409-416

47. Singh SK (2016): Middle East Respiratory Syndrome Virus Pathogenesis. Seminars in Respiratory and Critical Care Medicine 37, 572-577 
48. Travaglio M, Yu Y, Popovic R, Selley L, Leal NS, Martins LM (2021): Links between air pollution and COVID-19 in England. Environmental Pollution 268, 115859

49. Van Doremalen N, Bushmaker T, Morris DH, Holbrook MG, Gamble A, Williamson BN, Tamin A, Harcourt JL, Thornburg NJ, Gerber SI, Lloyd-Smith JO, de Wit E, Munster VJ (2020): Aerosol and Surface Stability of SARS-CoV-2 as Compared with SARS-CoV-1. New England Journal of Medicine $382,1564-1567$

50. Wan X, Cheng C, Zhang Z (2020): Early transmission of COVID-19 has an optimal temperature but late transmission decreases in warm climate. medRxiv, 2020.05.14.20102459

51. Wang B, Liu J, Li Y, Fu S, Xu X, Li L, Zhou J, Liu X, He X, Yan J, Shi Y, Niu J, Yang Y, Li Y, Luo B (2020): Airborne particulate matter, population mobility and COVID-19: a multi-city study in China. BMC Public Health 20, 1585

52. Wu X, Nethery RC, Sabath BM, Braun D, Dominici F (2020): Exposure to air pollution and COVID-19 mortality in the United States: A nationwide cross-sectional study. medRxiv, 2020.04.05.20054502

53. Yin Y, Wunderink RG (2018): MERS, SARS and other coronaviruses as causes of pneumonia. Respirology 23, 130-137

54. Zhou J, Qin L, Meng X, Liu N (2021): The interactive effects of ambient air pollutants-meteorological factors on confirmed cases of COVID-19 in 120 Chinese cities. Environ Sci Pollut Res Int, 1-11

55. Zhou P et al. (2020): A pneumonia outbreak associated with a new coronavirus of probable bat origin. Nature $579,270-273$

56. Zhu Y, Xie J, Huang F, Cao L (2020): Association between short-term exposure to air pollution and COVID-19 infection: Evidence from China. Science of The Total Environment 727, 138704

57. Zoran MA, Savastru RS, Savastru DM, Tautan MN (2020): Assessing the relationship between ground levels of ozone (03) and nitrogen dioxide (NO2) with coronavirus (COVID-19) in Milan, Italy. Science of The Total Environment 740, 140005

\section{Tables}

Table 1. Descriptive statistics of daily AIRBORNE pollutants and weather variables in 41 Chinese cities from January 20 to February 29, 2020. 


\begin{tabular}{|lccccccc|}
\hline Variables & Min & Q25 & Median & Q75 & Max & Mean & SD \\
\hline $\mathrm{PM}_{2.5}\left(\mu \mathrm{g} / \mathrm{m}^{3}\right)$ & 2.0 & 26.0 & 42.0 & 65.0 & 270.0 & 51.0 & 35.9 \\
\hline $\mathrm{PM}_{10}\left(\mu \mathrm{g} / \mathrm{m}^{3}\right)$ & 5.0 & 34.0 & 53.0 & 80.0 & 338.0 & 62.4 & 39.8 \\
\hline $\mathrm{NO}_{2}\left(\mu \mathrm{g} / \mathrm{m}^{3}\right)$ & 3.0 & 11.0 & 16.0 & 23.0 & 116.0 & 18.8 & 11.8 \\
\hline $\mathrm{SO}_{2}\left(\mu \mathrm{g} / \mathrm{m}^{3}\right)$ & 2.0 & 5.0 & 6.0 & 9.0 & 56.0 & 7.7 & 5.3 \\
\hline $\mathrm{CO}\left(\mathrm{mg} / \mathrm{m}^{3}\right)$ & 0.2 & 0.6 & 0.8 & 1.0 & 2.3 & 0.9 & 0.3 \\
\hline $\mathrm{O}_{3}\left(\mu \mathrm{g} / \mathrm{m}^{3}\right)$ & 5.0 & 58.0 & 76.0 & 94.0 & 150.0 & 75.9 & 23.4 \\
\hline Temperature $\left({ }^{\circ} \mathrm{C}\right)$ & -22.5 & 5.0 & 7.6 & 10.3 & 23.0 & 7.6 & 5.5 \\
\hline Relative humidity $(\%)$ & 9.3 & 65.2 & 75.8 & 86.8 & 100 & 74.7 & 15.2 \\
\hline
\end{tabular}

Table 2. Spearman correlations between airborne pollutants and meteorological variables in all cities during the study period

\begin{tabular}{|c|c|c|c|c|c|c|c|}
\hline Factors & $\mathrm{PM}_{2.5}$ & $\mathrm{PM}_{10}$ & $\mathrm{NO}_{2}$ & $\mathrm{SO}_{2}$ & $\mathrm{CO}$ & $\mathrm{O}_{3}$ & TEMP \\
\hline $\mathrm{PM}_{10}$ & $0.793^{\star \star}$ & & & & & & \\
\hline $\mathrm{NO}_{2}$ & $0.414^{\star \star}$ & $0.331^{*}$ & & & & & \\
\hline $\mathrm{SO}_{2}$ & $0.365^{\star}$ & 0.244 & $0.355^{\star}$ & & & & \\
\hline $\mathrm{CO}$ & $0.563^{\star *}$ & $0.390 *$ & 0.302 & $0.364 *$ & & & \\
\hline $\mathrm{O}_{3}$ & 0.196 & 0.193 & 0.056 & 0.068 & -0.118 & & \\
\hline TEMP & -0.834 ** & $-0.677 * \star$ & $-0.328^{*}$ & -0.307 & 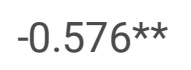 & -0.278 & \\
\hline $\mathrm{RH}$ & $-0.388^{*}$ & $-0.327 *$ & $-0.448^{*}$ & -0.012 & -0.155 & $-0.531^{* *}$ & $0.452^{\star \star \star}$ \\
\hline
\end{tabular}

Note: TEMP and RH indicate ambient temperature and relative humidity, respectively; * and ** indicate $\mathrm{P}<0.05$ and $\mathrm{P}<0.01$, respectively.

Table 3. Cumulative Effects estimates on different lag days of airborne pollutants in all cities 


\begin{tabular}{|lllll|}
\hline Lag days & $\mathrm{RR}(95 \% \mathrm{Cl})$ & & & \\
\hline Pollutants & $\mathrm{PM}_{2.5}$ & $\mathrm{O}_{3}$ & $\mathrm{SO}_{2}$ & $\mathrm{NO}_{2}$ \\
\hline Lag 0 & 1.006 & 1.010 & 1.052 & 1.004 \\
& $(1.002-1.009)$ & $(1.007-1.014)$ & $(1.022-1.083)$ & $(0.992-1.016)$ \\
\hline Lag 1 & 1.007 & 1.009 & 1.032 & 1.013 \\
& $(1.003-1.011)$ & $(1.005-1.013)$ & $(1.001-1.063)$ & $(0.996-1.029)$ \\
\hline Lag 2 & 1.007 & 1.007 & 1.030 & 1.008 \\
& $(1.004-1.011)$ & $(1.002-1.011)$ & $(0.996-1.065)$ & $(0.988-1.028)$ \\
\hline Lag 3 & 1.007 & 1.007 & 1.044 & 1.009 \\
& $(1.003-1.011)$ & $(1.002-1.012)$ & $(1.007-1.082)$ & $(0.989-1.030)$ \\
\hline Lag 4 & 1.010 & 1.007 & 0.997 & 1.017 \\
& $(1.005-1.014)$ & $(1.002-1.011)$ & $(0.958-1.038)$ & $(0.994-1.041)$ \\
\hline Lag 5 & 1.009 & 1.007 & 0.993 & 1.012 \\
& $(1.004-1.014)$ & $(1.002-1.012)$ & $(0.949-1.040)$ & $(0.991-1.033)$ \\
\hline Lag 6 & 1.008 & 1.005 & 1.003 & 0.999 \\
& $(1.004-1.013)$ & $(1.001-1.009)$ & $(0.956-1.052)$ & $(0.979-1.020)$ \\
\hline Lag 7 & 1.008 & 1.006 & 0.979 & 0.998 \\
& $(1.004-1.013)$ & $(1.000-1.013)$ & $(0.914-1.048)$ & $(0.981-1.015)$ \\
\hline Lag 0-1 & 1.003 & 1.011 & 0.999 & 0.995 \\
& $(1.000-1.007)$ & $(1.007-1.015)$ & $(0.961-1.038)$ & $(0.984-1.007)$ \\
& 1.005 & 1.009 & 1.039 & 1.004 \\
& $(1.000-1.011)$ & $(1.004-1.015)$ & $(0.982-1.100)$ & $(0.991-1.018)$ \\
\hline & 0.998 & 1.009 & 0.938 & 0.986 \\
& $(0.988-1.007)$ & $(1.001-1.017)$ & $(0.852-1.033)$ & $(0.968-1.006)$ \\
& 1.050 & 1.021 & 0.812 & 1.094 \\
& $(1.028-1.073)$ & $(0.994-1.049)$ & $(0.632-1.043)$ & $(1.028-1.164)$ \\
\hline
\end{tabular}

\section{Figures}




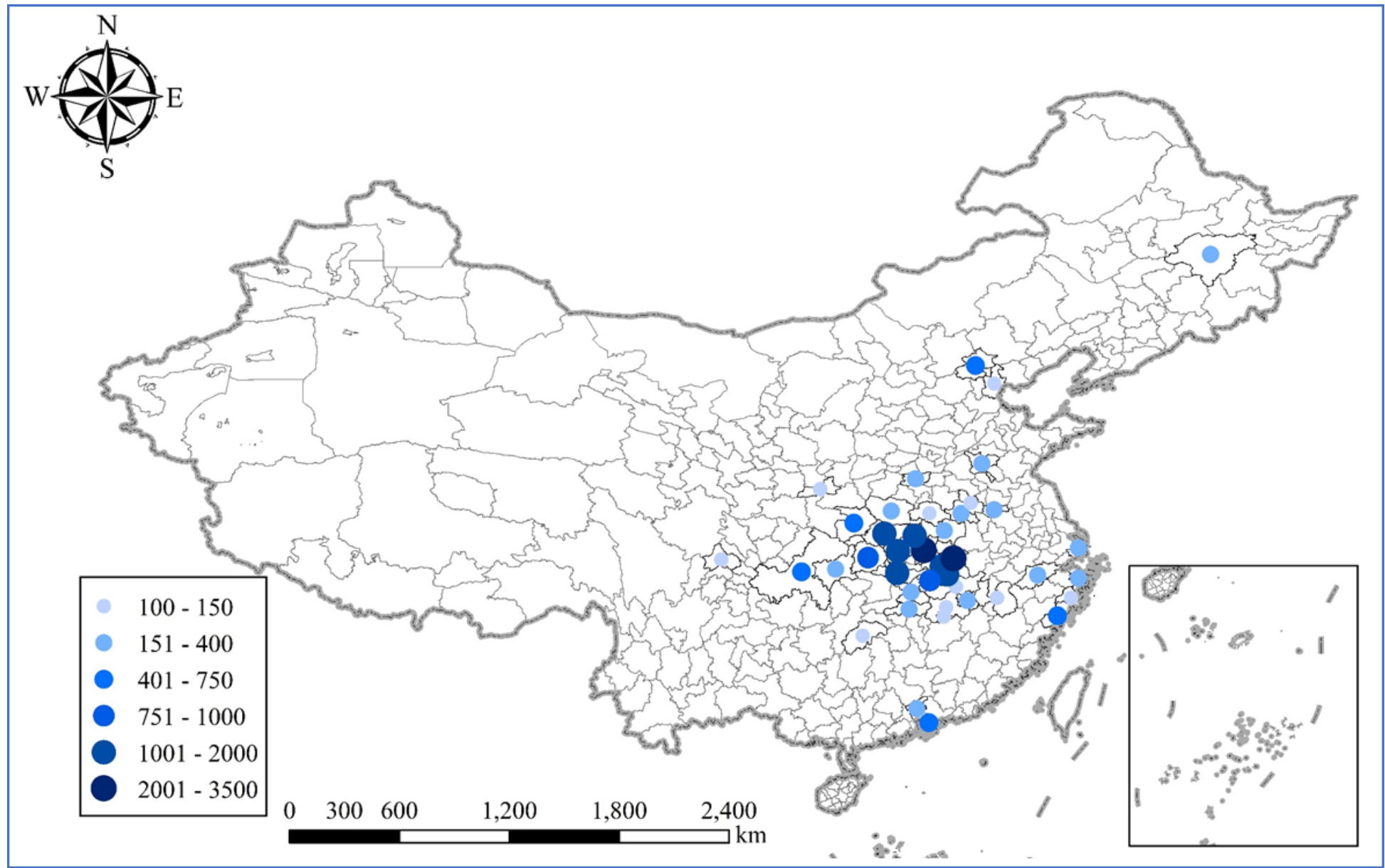

Figure 1

Cumulative confirmed cases in 41 Chinese cities from January 20 to February 29, 2020 Note: The designations employed and the presentation of the material on this map do not imply the expression of any opinion whatsoever on the part of Research Square concerning the legal status of any country, territory, city or area or of its authorities, or concerning the delimitation of its frontiers or boundaries. This map has been provided by the authors. 


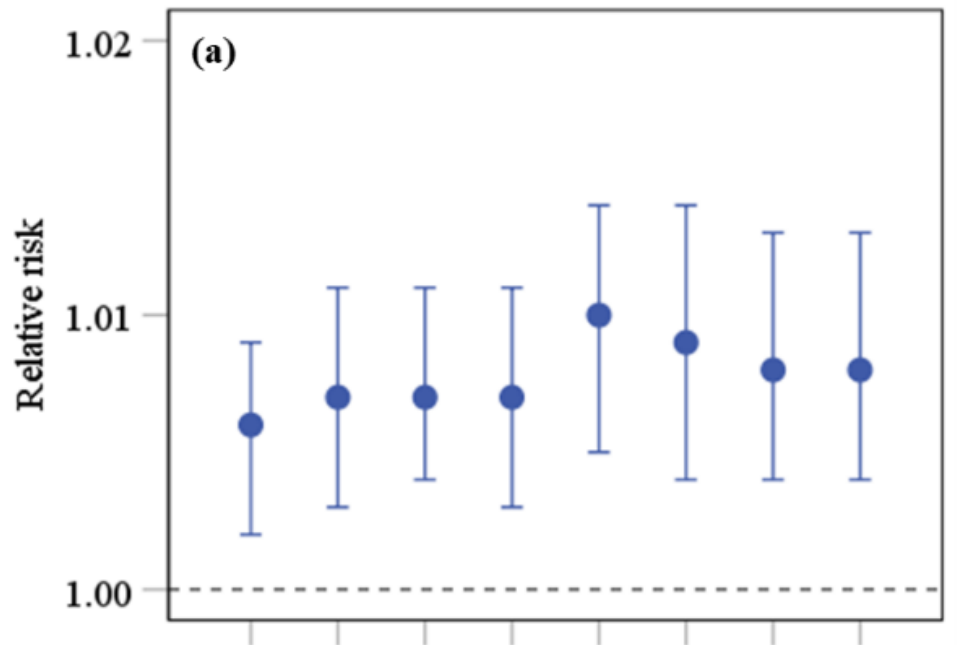

lag0 lag1 lag2 lag3 lag4 lag5 lag6 lag7

Lag days

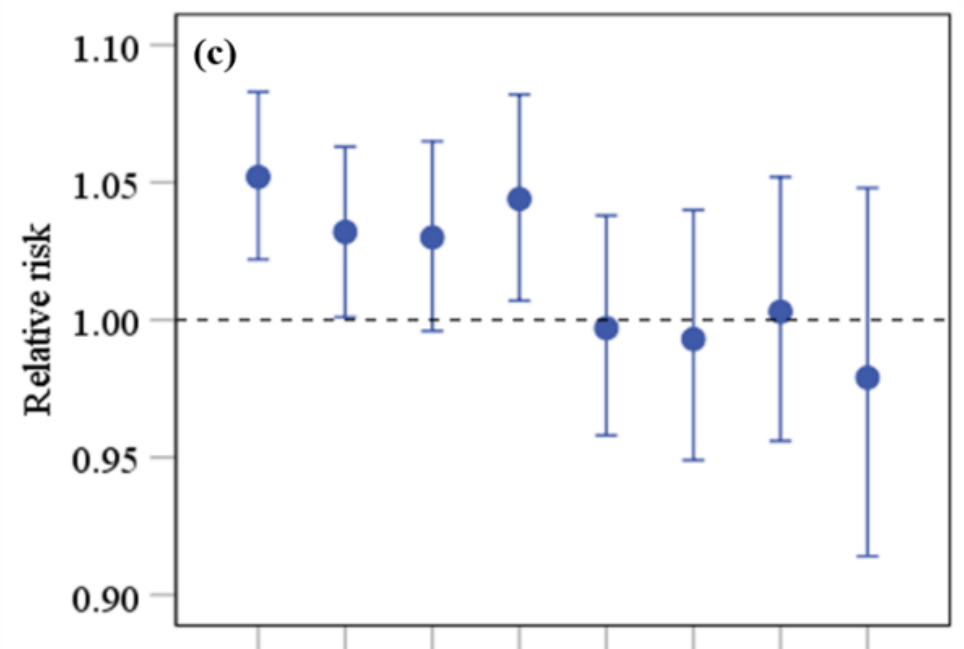

lag0 lag1 lag2 lag3 lag4 lag5 lag6 lag7

Lag days

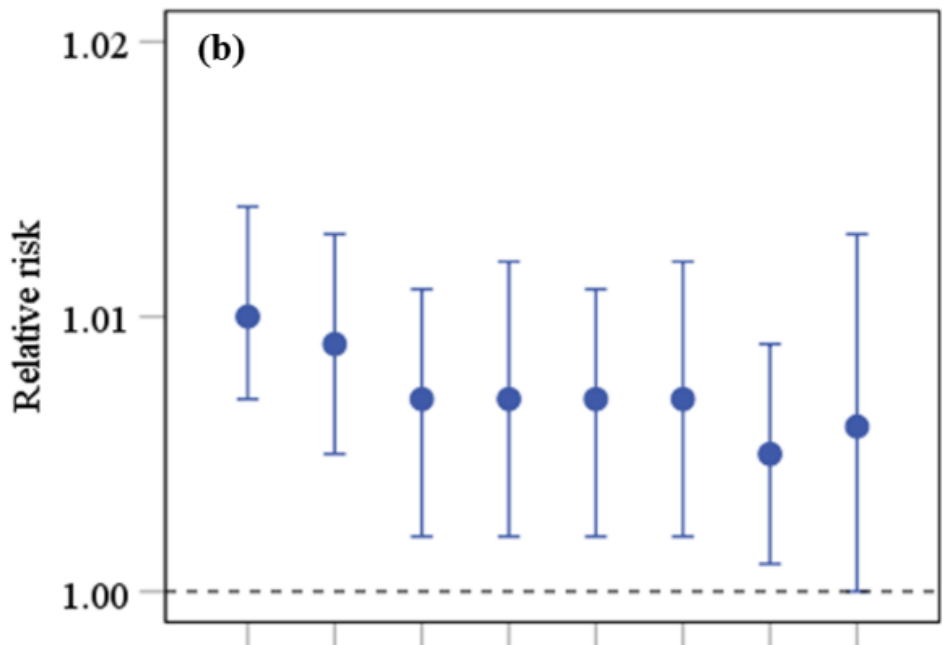

lag0 lag1 lag2 lag3 lag4 lag5 lag6 lag7

Lag days

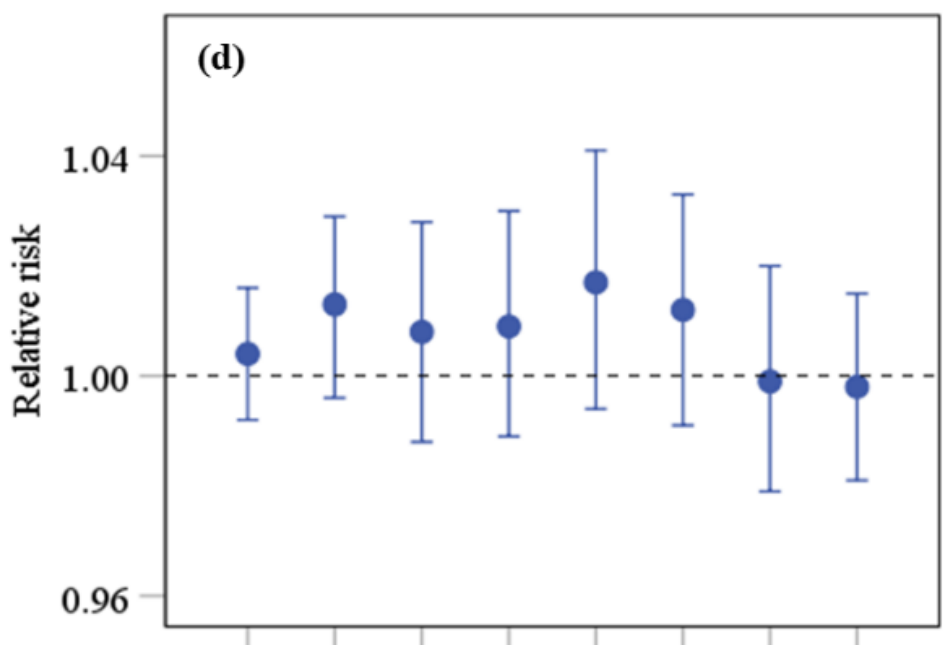

lag0 lag1 lag2 lag3 lag4 lag5 lag6 lag7

Lag days

Figure 2

Pooled relative risks of daily newly COVID-19 confirmed cases associated with (a) PM2.5, (b) 03, (c) SO2 and (d) NO2 Note: Error bars are $95 \%$ Cls. 


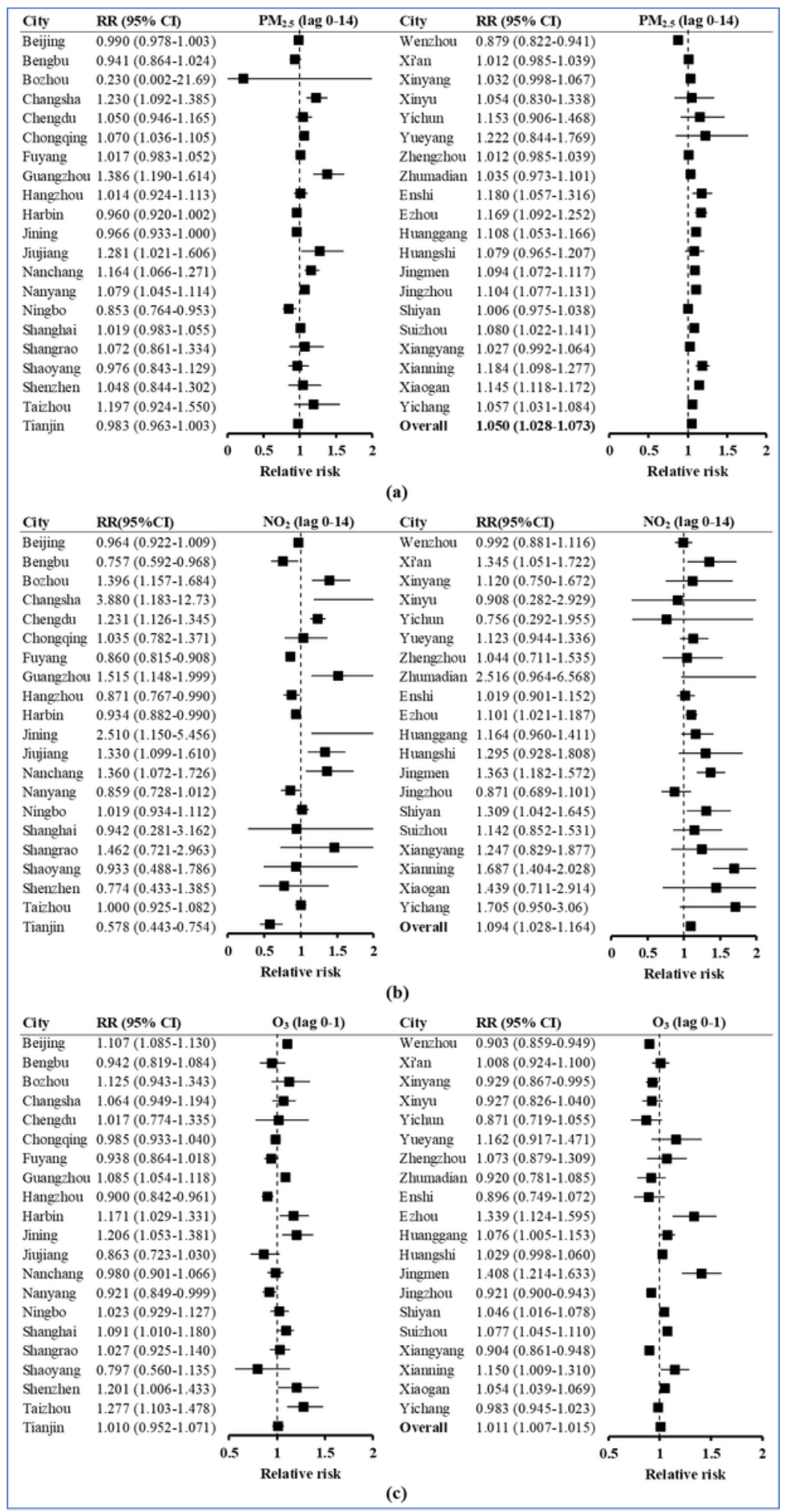

Figure 3

Forest plot for cumulative RRs $(95 \% \mathrm{Cl})$ of daily newly COVID-19 confirmed cases associated with a 10 $\mu \mathrm{g} / \mathrm{m} 3$ increase in (a) PM2.5 at lag 0-14; (b) NO2 at lag 0-14; (c) 03 at lag 0-1 

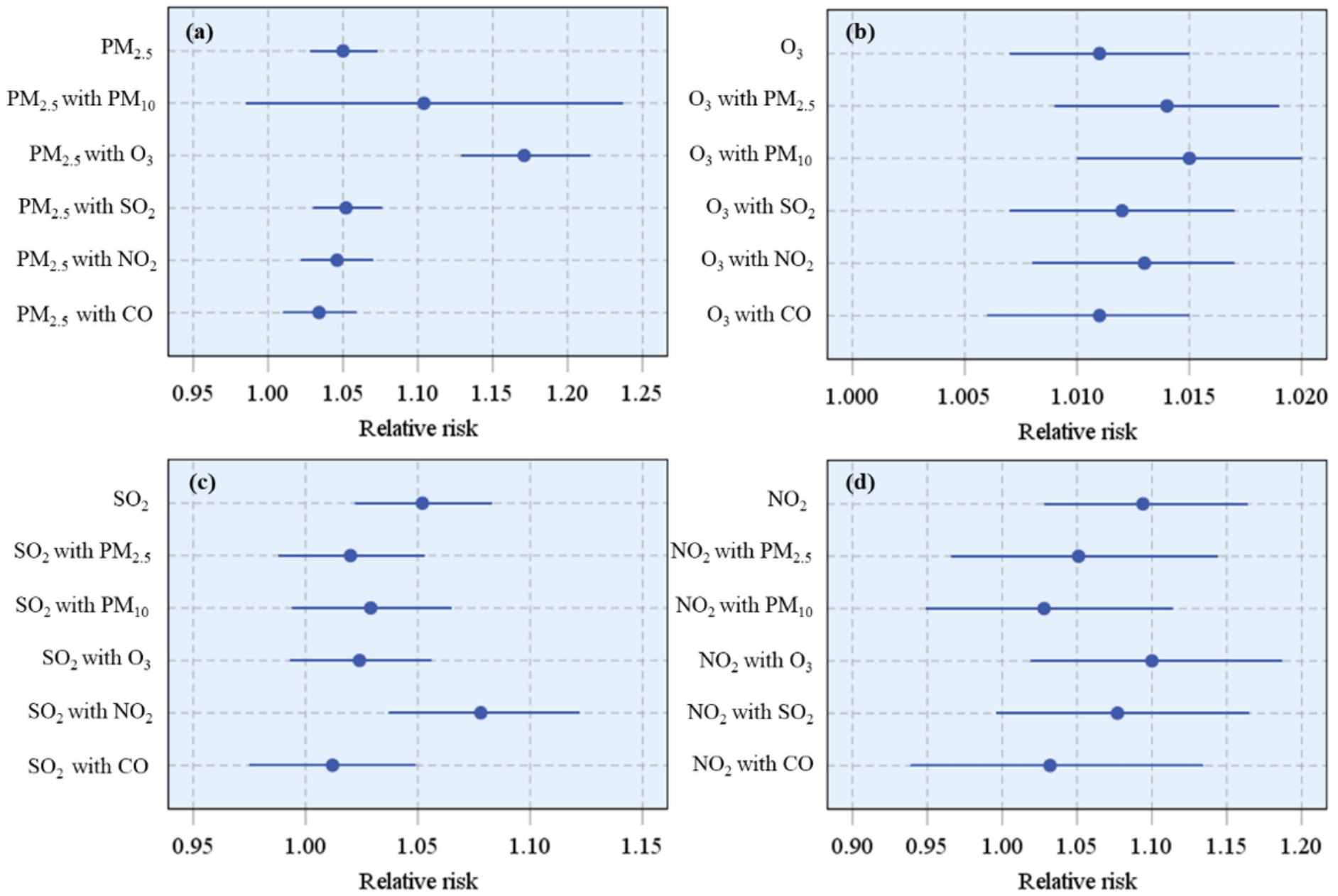

\section{Figure 4}

Pooled RRs $(95 \% \mathrm{Cl})$ of daily newly COVID-19 confirmed cases associated with a $10 \mu \mathrm{g} / \mathrm{m} 3$ rise in (a) PM2.5 at lag 0-14, (b) 03 at lag 0-1, (c) SO2 at lag 0 and (d) NO2 at lag 0-14, with and without adjustment for other airborne pollutants

\section{Supplementary Files}

This is a list of supplementary files associated with this preprint. Click to download.

- Supplementarymaterial.docx 